\title{
Technological Advances in The Dental Management of Patients with Lesch-Nyhan Syndrome: A Case Report
}

\author{
Alexandros Papagiannis ${ }^{1}$, Eftychia Pappa ${ }^{2 *}$, Christos Chryssafidis ${ }^{3}$, Evangelia Bogosian ${ }^{4}$ and Heleni Vastardis $^{5}$ \\ ${ }^{1}$ Orthodontist, Private Practice in Lamia, Greece \\ ${ }^{2}$ National and Kapodistrian University of Athens, School of Dentistry, Department of Operative Dentistry, Athens, Greece \\ ${ }^{3}$ Dentist, Private Practice in Athens, Greece \\ ${ }^{4}$ Dental Clinic, University General Hospital of Heraklion, Heraklion, Greece \\ ${ }^{5}$ National and Kapodistrian University of Athens, School of Dentistry, Department of Orthodontics, Athens, Greece
}

Submission: March 02, 2020; Published: March 31, 2021

*Corresponding author: Eftychia Pappa, National and Kapodistrian University of Athens, School of Dentistry, Department of Operative Dentistry, Athens, Greece

Keywords: Lesch-Nyhan syndrome, Self-mutilation, Behavioral modification, Digital dentistry, Virtual models, Intraoral splints

\section{Introduction}

Lesch-Nyhan syndrome (LNS) is a rare X-linked genetic disorder of purine metabolism [1], affecting the central nervous system [2]. It is a perfect example of a well-established molecular disorder that is consistently linked to a complex behavioral pattern [2]. The defective activity of the enzyme hypoxanthine-guanine phosphoribosyltransferase (HGPRT) $[3,4]$, catalyzing conversion of the purines hypoxanthine and guanine to the nucleotides inosine monophosphate and guanosine monophosphate respectively, leads to the concentration of large amounts of hypoxanthime, xanthine, and uric acid in blood [3,4]. Epistasis between the mutated hypoxanthine phosphoribosyltransferase 1 (HPRT1) and the amyloid precursor protein (APP) genes has been recently suggested [3]. The main tissues affected are brain, liver, and erythrocytes (megaloblastic anaemia is frequent; microcitic anaemia can also be present) $[4,5]$.

The neurological symptoms include dystonia, choreoathetosis, spasticity, hyperflexia and ballismus [1,6]. Behavioral clinical symptoms involve mental retardation (mean IQ approximately 60 although, individual scores of IQ equal to 15 have been reported [7]), cognitive dysfunction and the compulsion towards selfmutilation $[1,6]$. Lips, especially the lower one, cheeks, tongue and fingers are mostly mutilated by biting.

The current case report describes a child with Lesch-Nyhan syndrome who presented with self-injury of cheeks and lips and was treated conservatively with intraoral splints and mouthguards. Emphasis is given on the potential of digital dentistry in the management of such cases, where compliance is absent.

\section{Case Report}

A 5-year-old boy, previously diagnosed with LNS, was referred to the Dental Clinic of the University General Hospital of Heraklion, Crete, with self-mutilation of cheeks and tongue. He exhibited hyperflexia, abnormal movements and spasticity, a condition that worsened by increased tension and anxiety. Laboratory tests revealed hyperuricemia, implying excessive purine production. Intra- and extraoral examination revealed injured cheeks and lips.

Upper and lower intraoral impressions, from a resistant to deformation material (polyvinyl-siloxane), were taken under general anesthesia for the construction of appliances that could prevent the self-injurious behavior. It was decided to fabricate $2 \mathrm{~mm}$ thick upper and lower, soft on the inside and hard on the outside mouthguards. After their delivery, behavioral symptoms were alleviated, and self-mutilation ceased. Whenever it was difficult for the patient to retain the appliance, an adhesive material was also implemented. Unfortunately, splint damage often occurred, requiring subsequent replacements. Furthermore, after a 4-month period, the child started biting his fingers. A mouthguard of $3 \mathrm{~mm}$ thickness resembling a passive positioner was constructed to prevent further trauma (Figure 1). 
(a)

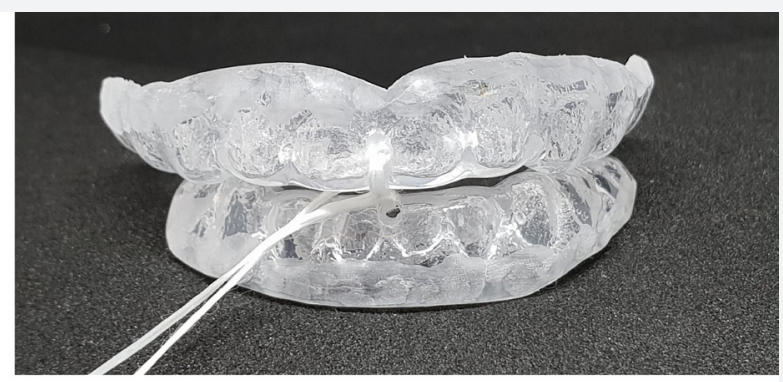

(b)

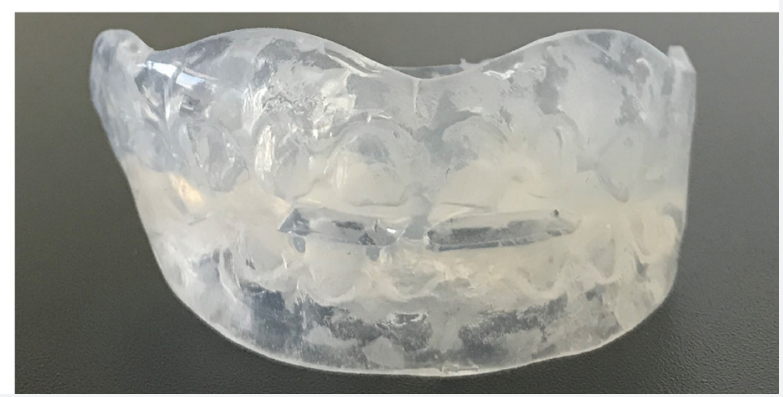

Figure 1: The intraoral (a) splints and (b) the mouthguard used for the modification of the self-injurious behavior.

The problem raised with time was that even the polyvinylsiloxane impressions were on the verge of permanent deformation. General anesthesia could not be conducted again, due to renal malfunction, a common finding in such patients. The solution to this problem was sought in digital dentistry procedures. The scanning of the initial plaster model provided us with a 3D virtual model of the teeth and perioral tissues. This enabled us to fabricate unlimited resin model casts, by $3 \mathrm{D}$ printing, that were used for direct construction of any intraoral appliance, eliminating the need for additional general anesthesia. Digital dental casts are presented in Figure 2.

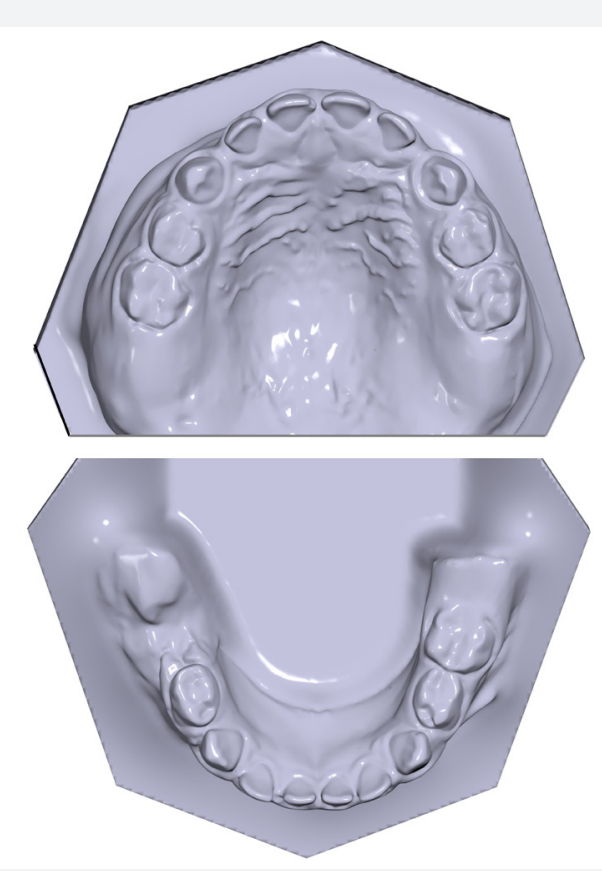

Figure 2: Three-dimensional virtual models of the teeth and the alveolar processes. 


\section{Discussion}

This case is an example of how dental technology and computer-assisted components can facilitate the management of complicated cases with minimal to no compliance. A similar approach could involve the use of an intra-oral scanner under mild sedation instead of general anesthesia. Three-dimensional printing of the virtual models, or even the direct design and fabrication of the splints and mouthguards by biocompatible printing materials could facilitate treatment and establish new ways of meeting patients' needs.

In this case, we decided to select intraoral splints and modified mouthguards as the preferred way to restrict the self-aggressive behavior. Many methods have been proposed in the literature for managing this condition. For the prevention of the lower lip injury, due to sucking habits, the construction of a mouthguard of $3 \mathrm{~mm}$ thickness, of a soft inner and hard outer part has been proposed [8]. In case that a more stable appliance is necessary, a lip-bumper constructed in a way that the distance between the lower teeth and the lower lip does not allow sucking, can offer an alternative solution [8]. The combination of a mouthguard in the upper jaw and a lip-bumper in the lower jaw has been associated with positive behavioral modification [8].

A modified intraoral resin mouthguard has also been proposed, presenting a hard side in contact with the teeth, to increase retention, and a soft side outside, to prevent traumatic occlusion. Any contact with the perioral tissues is removed, to increase its stability [9]. The use of acrylic splints with labially placed acrylic arch, soft mouthguards, bite plates or lower lip guards have been suggested as well $[10,11]$. Protection of fingers, hands and forearms with bandages can offer an effective management of the self-destructive behavior [4].

Drugs have been subscribed to prevent the self-injurious behavior, but with questionable results. Allopurinol has been extensively used to decrease the levels of uric acid to normal, but the neurological and behavioral aspect of the syndrome was not affected. Diazepam has also been used for relaxation of the muscular system [8].

The last and most invasive approach to prevent self-mutilation is extraction of teeth of both deciduous and permanent dentitions. This should be recommended only in extreme cases, and in case of significant medical complications $[10,12]$. Nonetheless, even after the extraction of the deciduous dentition, new forms of selfaggressiveness can be developed [13].

Less radical interventions such as the oral appliances could be the first step in managing LNS cases, opting for a positive behavioral modification. On this note, recent technology and digital dentistry can make clinical work easier and more effective for the patient. However, it has been argued [10] that deciduous dentition extraction at the initial stage would be better in some cases. Records of 5 patients with LNS treated conservatively with mouthguards were analyzed. Dental extractions of all teeth were eventually considered necessary in 4 out of the 5 cases. The disfigurement of the face and tongue from self-biting was thought more severe than the aesthetic effect of removing all the primary dentition [14]. Through this prism, the contribution of modern technology to easier and better management of such cases is invaluable.

\section{Acknowledgements}

We would like to thank the dental team, Dr. Vlasiadis Konstantinos and Dr. Parasiris Stavros, as well as the anesthesiologist Dr. Makatunaki Ekaterini who conducted the general anesthesia.

\section{Conflict of Interest}

We declare that we have no conflict of interest.

\section{References}

1. Lesch M, Nyhan WL (1964) A familiar disorder of uric acid metabolism and central nervous system function. Am J Med 36: 561-570.

2. Baumeister AA, Frye GD (1985) The Biochemical Basis of the Behavioral Disorder in the Lesch-Nyhan Syndrome. Neurosci Biobehav Rev 9(2): 169-178.

3. Nguyen KV, Naviaux RK, Nyhan WL (2020) Lesch-Nyhan disease: I. Construction of expression vectors for hypoxanthine-guanine phosphoribosyltransferase (HGprt) enzyme and amyloid precursor protein (APP). Nucleosides Nucleotides Nucleic Acids 39(6): 905-922.

4. Scully C (1981) The orofacial manifestations of the Lesch-Nyhan syndrome. Int J Oral Surg 10(5): 380-383.

5. Torres RJ, Puig JG (2007) Hypoxanthine-guanine phosophoribosyltransferase (HPRT) deficiency: Lesch-Nyhan syndrome. Orphanet J Rare Dis 2: 48.

6. Neychev VK, Mitev VI (2004) The biochemical basis of the neurobehavioral abnormalities in the Lesch-Nyhan syndrome: a hypothesis. Med Hypotheses 63(1): 131-134.

7. Scherzer AL, Ilson JB (1965) Normal intelligence in the Lesch-Nyhan syndrome. Pediatrics 44(1): 116-120.

8. Cauwels RG, Martens LC (2005) Self-mutilation behavior in LeschNyhan syndrome. J Oral Pathol Med 34(9): 573-575.

9. Ragazzin G, Delucchi A, Calcagno E, Serretto R, Denotti G (2014) A modified intraoral resin mouthguard to prevent self-mutilations in Lesch-Nyhan patients. Int J Dent 2014: 396830.

10. Rasid N, Yusuf H (1997) Oral self-mutilation by a 17-month-old child with Lesch-Nyhan syndrome. Int J Paediatr Dent 7(2): 115-117.

11. Jeong TS, Lee JH, Kim S, Kim JH, Tootla RG (2006) A preventive approach to oral self-mutilation in Lesch-Nyhan syndrome: a case report. Pediatr Dent 28(4): 341-344.

12. Benz CM, Reeka-Bartschmid AM, Agostini FG (2004) Case report: the Lesch-Nyhan syndrome. Eur J Paediatr Dent 5(2): 110-114.

13. de la Cuadra LG, Torres RG, Beltrán LM, Sánchez A, Puig JG (2016) Development of new forms of self-injurious behavior following total dental extraction in Lesch-Nyhan disease. Nucleosides, Nucleotides and Nucleic Acids 35(10-12): 524-528.

14. Goodman EM, Torres RJ, Puig JG, Jinnah HA (2014) Consequences of Delayed Dental Extraction in Lesch-Nyhan Disease. Mov Disord Clin Pract 1(3): 225-229. 
Your next submission with Juniper Publishers will reach you the below assets

- Quality Editorial service

- Swift Peer Review

- Reprints availability

- E-prints Service

- Manuscript Podcast for convenient understanding

- Global attainment for your research

- Manuscript accessibility in different formats

( Pdf, E-pub, Full Text, Audio)

- Unceasing customer service

Track the below URL for one-step submission

https://juniperpublishers.com/online-submission.php 